\title{
Controversies on the treatment of ovarian cancer with dose-dense chemotherapy
}

\author{
Alberto Súarez-Zaizar ${ }^{1}$, Eduardo Cárdenas-Cárdenas ${ }^{1}$, Yadira Araceli Barajas-Castro², \\ Patricia Cortés-Esteban ${ }^{1}$
}

${ }^{1}$ Oncology Service, Centro Médico Nacional 20 de Noviembre, Instituto de Salud y Seguridad Social de los Trabajadores del Estado, Mexico City, México; ${ }^{2}$ Oncology Service, Hospital de la Mujer, Secretaría de Salubridad y Asistencia, México City, México

Contributions: (I) Conception and design: P Cortés-Esteban, A Súarez-Zaizar; (II) Administrative support: P Cortés-Esteban, E Cárdenas-Cárdenas, YA Barajas-Castro; (III) Provision of study materials or patients: P Cortés-Esteban, A Súarez-Zaizar; (IV) Collection and assembly of data: P CortésEsteban, A Súarez-Zaizar, E Cárdenas-Cárdenas; (V) Data analysis and interpretation: All authors; (VI) Manuscript writing: All authors; (VII) Final approval of manuscript: All authors.

Correspondence to: Dr. Patricia Cortés-Esteban. Medical Oncologist at Centro Médico Nacional 20 de Noviembre, Instituto de Salud y Seguridad Social de los Trabajadores del Estado, Av. Félix Cuevas 540, colonia del Valle, delegación Benito Juárez, Ciudad de México, México.

Email: dra.pcortes@gmail.com.

\begin{abstract}
Epithelial ovarian cancer is the most lethal gynaecological malignancy with an estimated 295,414 new cases and 184,799 deaths around the world. Cytoreductive surgery and combination chemotherapy have remained a standard therapy for decades. The majority of women diagnosed with ovarian cancer will receive systemic chemotherapy for recurrent or advanced diseased. In recent years, therapies such as anti-angiogenics, PARP inhibitors, and dose-dense chemotherapy have emerged as novel strategies against ovarian cancer. Dose-dense chemotherapy, usually with a carboplatin and paclitaxel regimen, has been proposed as an alternative to conventional chemotherapy for these patients. However, the results for different trails are inconsistent and dose-dense chemotherapy remains controversial. Results from the JGOG 3016 study showed a progression free survival and overall survival benefit, with increased neurotoxicity and anaemia. While the GOG 262, MITO-7, GOG 252 and ICON8 studies found no benefit on progression free survival, with a recent meta-analysis concluding that three weekly chemotherapy remains the standard of care. Ovarian cancer molecular subtypes and differences in pharmacogenetics between populations may explain the differences in response to dose dense chemotherapy, however our understanding of this factors is still lacking. Here, we reviewed the evidence for and against dose-dense chemotherapy and the possible factors for the different results among trials.
\end{abstract}

Keywords: Epithelial ovarian cancer (EOC); chemotherapy; taxanes

Submitted Feb 12, 2020. Accepted for publication Jul 19, 2020.

doi: 10.21037/cco-2019-oc-12

View this article at: http://dx.doi.org/10.21037/cco-2019-oc-12

\section{Introduction}

Epithelial ovarian cancer (EOC) is recognized as a heterogeneous disease with the highest lethality among gynaecological malignancies. In 2018, the GLOBOCAN database estimated there were 295,414 new cases and 184,799 deaths from EOC (1). The GLOBOCAN database predicts that by 2040 there will be a worldwide increase in incidence and mortality, reaching 434,184 new cases and 293,039 deaths per year respectively (2). The majority of women are diagnosed with advanced International Federation of Gynaecology and Obstetrics (FIGO) stage III/IV disease and over $75 \%$ of patients diagnosed with ovarian cancer will recur and die from this disease. Cytoreductive surgery and combination platinumtaxane chemotherapy have remained a standard therapy for decades. Other systemic therapies such as anti-angiogenics, 
PARP inhibitors, and dose-dense chemotherapy have emerged as novel strategies against ovarian cancer $(3,4)$.

In principle, the cancer cell has a higher exposure with a dose-dense approach, therefore limiting the surge of resistance in those cells; this in turn enhances the antineoplastic activity. Additionally, when using paclitaxel once a week, instead of three-weekly, an anti-angiogenic effect is in place (5). In a phase II study, $80 \mathrm{mg} / \mathrm{m}^{2}$ paclitaxel and carboplatin at a target area under the curve (AUC) of 2, were administered every week to recurrent ovarian cancer patients, a $67 \%$ response rate was achieved (6), which led to phase III studies that were revised in various publications and guides (7-10). However, dose-dense chemotherapy and its benefits remain controversial, so we revised the main studies to help guide the decision on the use of this type of chemotherapy.

\section{Dose-dense therapy: evidence found in phase III studies}

The Japanese Gynecologic Oncology Group's (JGOG) 3016 New Ovarian Elaborate (NOVEL) (11) study was the first phase III clinical trial to include 637 patients with epithelial ovarian, fallopian tube, or primary peritoneal cancer in stages two to four; individuals were assigned randomly to regimes of dos dense paclitaxel and carboplatin or conventional treatment. After a median follow up of 76.8 months, the median progression free survival (PFS) was better in those individuals with a dose-dense regime (28 months) than those in the three weekly (17.2 months), with a statistically significant hazard ratio (HR) of 0.71 [95\% confidence interval (CI): 0.58-0.88]. Furthermore, the overall survival (OS) favoured the paclitaxel dose-dense group with an HR of 0.75 (95\% CI: 0.57 to $0.98, \mathrm{P}=0.03$ ). On the other hand, there was no significant difference in the response rate between arms.

The most common adverse event was neutropenia with 286 of 312 patients (92\%) in the dose-dense regimen and 276 of 314 patients $(88 \%)$ in the conventional regimen. A statistically significant difference of anaemia (grade 3/4) was found, with a higher prevalence in the subjects with the dose-dense treatment (69\%) compared to the other group (44\%). The frequencies of other toxic effects were similar between groups (11). Median overall survival was 100.5 months in the dose-dense treatment group and 62.2 months in the conventional treatment group (HR 0.79, 95\% CI: 0.63-0.99; $\mathrm{P}=0.039)$. With these results, dosedense chemotherapy was seen as a possible new standard for treatment in 2013 (12).

The Multicentre Italian Trials in Ovarian cancer trial (MITO-7) (13), initiated an open label trial with 810 individuals with ovarian cancer in a FIGO stage IC to IV, 404 patients received standard chemotherapy with carboplatin (AUC $6 \mathrm{mg} / \mathrm{mL} / \mathrm{min}$ ) and paclitaxel $\left(175 \mathrm{mg} / \mathrm{m}^{2}\right.$ ) three weekly for a total of six cycles and 406 patients received an established regimen of weekly carboplatin (AUC $2 \mathrm{mg} / \mathrm{mL} / \mathrm{min}$ ) plus paclitaxel $\left(60 \mathrm{mg} / \mathrm{m}^{2}\right)$ for 18 consecutive weeks. The weekly regimen did not have a beneficial effect over PFS, having an HR of 0.96 (95\% CI: 0.8 to $1.16, \mathrm{P}=0.66)$. However, it was associated with a better quality of life and a lower toxicity rate, making such regimen an alternative for poor performance status patients. Noted, strictly a dose-dense paclitaxel method was not used.

The most common adverse events found in the every 3 week treatment group, were grade 3-4 neutropenia in 167 of 399 patients (42\%) compared to 200 out of 400 patients $(50 \%)$ in the weekly group, febrile neutropenia (2 vs. 11), thrombocytopenia grade 3-4 (4 vs. 27), and neuropathy grade $\geq 2$ (24 vs. 68) (13).

An open-label and randomized phase 3 trial-the GOG 0262 study (14), included 692 patients with ovarian cancer. Two regimens were compared, the first one included intravenous paclitaxel at a $175 \mathrm{mg} / \mathrm{m}^{2}$ dose, administered as a 3 hours infusion on the first day in addition to intravenous carboplatin at an AUC of 6, also on day 1 of the cycle, and a total of six cycles (21-day cycle). The second regimen included $80 \mathrm{mg} / \mathrm{m}^{2}$ of body surface area intravenous paclitaxel, over one hour on days one, eight, and fifteen (21-day cycle), in addition to intravenous carboplatin (AUC =6) on the first day of each of the total 6 cycles. At the median 28 months follow-up, there was a $67 \%$ survival rate. The intention-to-treat analysis revealed a lack of effect in PFS of the weekly paclitaxel compared to the one administered every three weeks [14.7 compared to 14 months; HR 0.89 (95\% CI: 0.74-1.06, $\mathrm{P}=0.18$ )]. An ancillary analysis in individuals who did not receive bevacizumab, PFS was improved significantly by the weekly paclitaxel regimen, adding 3.9 months of PFS when compared to the other regimen. This points to the possible additive effect of anti-angiogenic therapy in adjuvant treatment. On the other hand, those in the weekly paclitaxel group experienced more frequently grade 3-4 anemia and also of grade 2-4 neuropathy; with a lower frequency of grade 3-4 neutropenia.

In the recent ICON 8 trial (15), where 1,566 women with an epithelial ovarian cancer in a FIGO stage IC to IV 
were included after primary cytoreductive surgery (IPS) or before receiving neoadjuvant chemotherapy for intended delayed primary cytoreductive surgery (DPS). Study population characteristics were a median age of 62 years, $93 \%$ had a good performance status (ECOG 0 or 1), $69 \%$ had high grade serous carcinoma, and $72 \%$ presented with advanced (stage IIIC) disease. There were three groups randomly assigned, each receiving a different regimen (1:1:1): group 1 carboplatin at either AUC5 or AUC6 and paclitaxel $175 \mathrm{mg} / \mathrm{m}^{2}$ every first day of a three-week cycle for a total of 6 cycles; the second group received the same 6 cycles of three weekly carboplatin dose in addition to weekly paclitaxel $80 \mathrm{mg} / \mathrm{m}^{2}$; and the third group was given weekly carboplatin AUC2 and paclitaxel $80 \mathrm{mg} / \mathrm{m}^{2}$ for a total of 18 weeks. None of the weekly regimens showed a PFS improvement and OS is not reported. A higher incidence of uncomplicated neutropenia in the dose-dense groups, with $15 \%$ vs. $35 \%$ vs. $30 \%$ in groups 1,2 and 3 respectively. Febrile neutropenia occurred in $4 \%, 6 \%$ and $3 \%$ of patients respectively. No difference in sensory neuropathy of grade $\geq 2$ was observed between groups.

In a meta-analysis published by Marchetti et al. (16), four randomized controlled trials were included with a total of 3,698 patients. In such study, it was determined that dosedense chemotherapy does not significantly improve PFS (HR 0.92, 95\% CI: 0.81-1.04, $\mathrm{P}=0.20$ ) versus standard regimen. With the absence of PFS superiority of dose-dense schedule, the authors conclude that the standard of care for advanced EOC should continue to be the conventional every 3 -week schedule.

\section{Factors associated to dose-dense chemotherapy response}

Dose-dense chemotherapy in ovarian cancer remains a controversial topic, as seen in the studies previously described. Different factors influence the results to dosedense therapy. Histological and molecular subtypes with diverse clinical features, chemotherapeutic responses and prognoses, as identified by Tan \& cols. (17), 5 molecular subtypes (Epithelial-A, Epithelial-B, Mesenchymal, Stemlike-A, and Stem-like-B) of EOC, being Stem-like-A the one with the worst prognosis along with increased microtubule activity that would render this group more resistance to paclitaxel. The Australian Ovarian Cancer Study (AOCS) and The Cancer Genome Atlas (TCGA) also identified subtypes based on genomic profiling of high-grade serous ovarian carcinoma: mesenchymal, immunoreactive, differentiated and proliferative. Of these subtypes, the mesenchymal has the poorest OS (median of 26.3 months) (18). The difference in survival among the four molecular subtypes may be due to difference in their response to chemotherapy, some having a higher resistance to platinum therapy, but higher sensitivity to taxanes, as seen in the Japanese Gynecologic Oncology Group study (JGOG3016A1), where conventional and dosedense carboplatin plus paclitaxel were compared among the four subtypes. Altogether, the mesenchymal subtype exhibited the worst PFS (median $1.4 \mathrm{y}$ ) and OS (median $3.6 \mathrm{y}$ ). With the previously stated, the mesenchymal subtype had a better outcome in the dose-dense group than in the conventional chemotherapy group, resulting in a longer PFS (median $1.8 \mathrm{y}$ versus 1.2 respectively) (18).

Another important factor to consider when using dosedense chemotherapy is the relationship that Breast Cancer (BRCA) 1/2 mutations have with a decreased sensitivity to taxanes. Furthermore, BRCA 1 may prove useful as a predictive biomarker to platinum chemotherapy in EOC, with BRCA1 deficiency anticipating greater response, although it also reduces response to taxanes (19).

Finally, it is important to stress that genetic differences, in addition to the pharmacogenetics of taxanes, have been proposed as the reason behind the variability in outcomes to dose-dense chemotherapy between the Japanese and Western populations. Genetic variations that come with ethnic differences may influence the pharmacokinetics and pharmacodynamics of paclitaxel (20). The cytochrome CYP3A5 gene allele found in Caucasian patients is non-functional, contributing to an increase in toxicity due to a lower metabolism of paclitaxel (21). A normal CYP3A5 function is more frequently seen among AfricanAmerican population (73\%) followed by Japanese (29\%) and Caucasians (22). However, there is still a gap to be filled regarding the role and clinical implications of these pharmacogenetic variability.

\section{Conclusions}

The benefit of dose-dense regimen remains controversial, the only positive study is JGOG 3016, where a benefit in PFS and OS was observed, displaying only increases in neurotoxicity and anaemia. However, there are 4 negative studies where there is no impact on PFS (GOG 262, MITO-7, GOG 252 and ICON8) and one study with no OS benefit (MITO-7), with a meta-analysis concluding that three weekly chemotherapy remains the standard of care. Dose-dense chemotherapy can be used safely in the 
treatment for EOC but does not significantly improve survival outcomes compared with standard three weekly chemotherapy in western populations. In order to have a true individualized systemic therapy, factors from different perspectives such as clinical, genetic and histological studies should be incorporated in future trials.

\section{Acknowledgments}

We thank Dr. Mario Ulises Pérez-Zepeda, from Geriatric Epidemiology Research Department, Instituto Nacional de Geriatría, México for his support in the development of this work.

Funding: None.

\section{Footnote}

Provenance and Peer Review: This article was commissioned by the Guest Editor (Heriberto Medina-Franco) for the series "Ovarian Cancer" published in Chinese Clinical Oncology. The article was sent for external peer review organized by the Guest Editor and the editorial office.

Conflicts of Interest: The authors have completed the ICMJE uniform disclosure form (available at http://dx.doi. org/10.21037/cco-2019-oc-12). The series "Ovarian Cancer" was commissioned by the editorial office without any funding or sponsorship. The authors have no other conflicts of interest to declare.

Ethical Statement: The authors are accountable for all aspects of the work in ensuring that questions related to the accuracy or integrity of any part of the work are appropriately investigated and resolved.

Open Access Statement: This is an Open Access article distributed in accordance with the Creative Commons Attribution-NonCommercial-NoDerivs 4.0 International License (CC BY-NC-ND 4.0), which permits the noncommercial replication and distribution of the article with the strict proviso that no changes or edits are made and the original work is properly cited (including links to both the formal publication through the relevant DOI and the license). See: https://creativecommons.org/licenses/by-nc-nd/4.0/.

\section{References}

1. Bray F, Ferlay J, Soerjomataram I, et al. Global cancer statistics 2018: GLOBOCAN estimates of incidence and mortality worldwide for 36 cancers in 185 countries. CA Cancer J Clin 2018;68:394-424.

2. Bhatla N, Jones A. The World Ovarian Cancer Coalition Atlas. World Ovarian Cancer Coalition 2018;27:1-39.

3. Lheureux S, Braunstein M, Oza AM. Epithelial ovarian cancer: Evolution of management in the era of precision medicine. CA Cancer J Clin 2019;69:280-304.

4. Banerjee S, Kaye SB. New strategies in the treatment of ovarian cancer: Current clinical perspectives and future potential. Clin Cancer Res 2013;19:961-8.

5. Norton L. Theoretical Concepts and the Emerging Role of Taxanes in Adjuvant Therapy. Oncologist 2001;6:30-5.

6. Katsumata N, Watanabe T, Mukai H, et al. A phase II trial of weekly paclitaxel/carboplatin (TJ) as salvage chemotherapy in patients with relapsed ovarian cancer. Proc Am Soc Clin Oncol 2001;20:abstr 865.

7. Katsumata N. Dose-dense therapy is of benefit in primary treatment of ovarian cancer? Ann Oncol 2011;22 Suppl 8:viii29-viii32.

8. Lee MX, Tan DS. Weekly versus 3-weekly paclitaxel in combination with carboplatin in advanced ovarian cancer: Which is the optimal adjuvant chemotherapy regimen? J Gynecol Oncol 2018;29:e96.

9. Colombo N, Sessa C, Bois A Du, et al. ESMO-ESGO consensus conference recommendations on ovarian cancer: Pathology and molecular biology, early and advanced stages, borderline tumours and recurrent disease. Int J Gynecol Cancer 2019;29:728-60.

10. National Comprehensive Cancer Network (NCCN). NCCN Clinical Practice Guideline in Oncology - Ovarian Cancer Including Fallopian Tube Cancer and Primary Peritoneal Cancer Version 3.2019 Available online: http:// www.nccn.org/professionals/physician_gls/pdf/ovarian.pdf

11. Katsumata N, Yasuda M, Takahashi F, et al. Dose-dense paclitaxel once a week in combination with carboplatin every 3 weeks for advanced ovarian cancer: a phase 3, open-label, randomised controlled trial. Lancet 2009;374:1331-8.

12. Katsumata N, Yasuda M, Isonishi S, et al. Long-term results of dose-dense paclitaxel and carboplatin versus conventional paclitaxel and carboplatin for treatment of advanced epithelial ovarian, fallopian tube, or primary peritoneal cancer (JGOG 3016): A randomised, controlled, open-label trial. Lancet Oncol 2013;14:1020-6.

13. Pignata S, Scambia G, Katsaros D, et al. Carboplatin plus paclitaxel once a week versus every 3 weeks in patients with advanced ovarian cancer (MITO-7): A randomised, 
multicentre, open-label, phase 3 trial. Lancet Oncol 2014;15:396-405.

14. Chan JK, Brady MF, Penson RT, et al. Weekly vs. Every3-Week Paclitaxel and Carboplatin for Ovarian Cancer. N Engl J Med 2016;374:738-48.

15. Clamp A, James E, McNeish I, et al. Weekly dose-dense chemotherapy in first-line epithelial ovarian, fallopian tube, or primary peritoneal carcinoma treatment (ICON8): primary progression free. Lancet 2019;394:2084-95.

16. Marchetti C, De Felice F, Di Pinto A, et al. Dose-dense weekly chemotherapy in advanced ovarian cancer: An updated meta-analysis of randomized controlled trials. Crit Rev Oncol Hematol 2018;125:30-4.

17. Tan TZ, Miow QH, Huang RY, et al. Functional genomics identifies five distinct molecular subtypes with clinical relevance and pathways for growth control in epithelial ovarian cancer. EMBO Mol Med 2013;5:1051-66.

18. Murakami R, Matsumura N, Michimae H, et al. The mesenchymal transition subtype more responsive

Cite this article as: Súarez-Zaizar A, Cárdenas-Cárdenas E, Barajas-Castro YA, Cortés-Esteban P. Controversies on the treatment of ovarian cancer with dose-dense chemotherapy. Chin Clin Oncol 2020;9(4):53. doi: 10.21037/cco-2019-oc-12 to dose-dense taxane chemotherapy combined with carboplatin than to conventional taxane and carboplatin chemotherapy in high grade serous ovarian carcinoma: A survey of Japanese Gynecologic Oncology Group study (JGOG3016A1). Gynecol Oncol 2019;153:312-9.

19. Quinn JE, Carser JE, James CR, et al. BRCA1 and implications for response to chemotherapy in ovarian cancer. Gynecol Oncol 2009;113:134-42.

20. Hertz DL. Germline pharmacogenetics of paclitaxel for cancer treatment. Pharmacogenomics 2013;14:1065-84.

21. Gandara DR, Kawaguchi T, Crowley J, et al. JapaneseUS common-arm analysis of paclitaxel plus carboplatin in advanced non-small-cell lung cancer: A model for assessing population-related pharmacogenomics. J Clin Oncol 2009;27:3540-6.

22. Hustert E, Haberl M, Burk O, et al. The genetic determinants of the CYP3A5 polymorphism. Pharmacogenetics 2001;11:773-9. 